\title{
MULTIPLE INTELLIGENCE THEORY AND ITS APPLICATION IN THE FOREIGN LANGUAGE CLASSROOM
}

\author{
Sanja Čukić \\ Faculty of Business and Industrial Management of the "Union" University Belgrade, \\ Belgrade, Serbia
}

\section{(C) MESTE NGO}

JEL category: 12, 120, 121, 129

\begin{abstract}
Howard Gardner's theory of multiple intelligence which appeared in the 1980's, was a revolutionary work that changed traditional perspective on human mind and learning. In the beginning, the theory was approached with doubt, since it opposed the belief that intelligence was an inherited, single entity, measured by IQ tests. According to this theory, there are eight types of intelligence which are to a certain extent present in each individual, and can be developed with practice. This means that there are different types of learners who are, depending on their type of intelligence, able to adopt certain materials more efficiently than others. The imperative of the theory was the change of curriculum and its adjustment to all eight types of learners. In accordance with this fact, many educators, who recognized the differences in learning among their students, applied this theory in order to enhance the quality of teaching. The purpose of this paper is to show the importance of this theory in ESL, as well as many different possibilities of applying it in a classroom. The attention will also be paid to some activities suitable for eight types of intelligence which can be used in the FL classroom. The topics that this paper is exploring could be interesting not only to English teachers, but to all educators.
\end{abstract}

Keywords: Howard Gardner, Multiple intelligence theory, education, FL classroom

\section{INTRODUCTION}

Howard Gardner's theory of multiple intelligence presents a significant contribution to cognitive science and a popular approach which points out that all students are unique. In accordance with this theory, many methods of understanding and facing the differences between people have been developed lately. (Richards \& Rodgers, 2001) The theory about eight different types of intelligence has been developed as a response to

The address of the author:

Sanja Čukić

拝三” cukic.sanja@gmail.com the understanding that individual cognitive differences should be recognized and approaches to them developed in a classroom. With the help of his coworkers, Gardner has identified the following types of intelligence: logical-mathematical intelligence, verbal intelligence, musical intelligence, bodilykinesthetic intelligence, interpersonal intelligence, intrapersonal intelligence, spatial intelligence and naturalistic intelligence. (Gardner, 1985) Gardner understood these different types of intelligence as tools which each individual has in order to save new information and make them more meaningful and more approachable. Each of 
these types of intelligence has equal significance. None of them is considered better or more important than the other. The only question imposed is: to what extend an individual possesses each of them, and what are their chances to develop some of them? Every one of us has all of these types of intelligence, but some of them are more developed or more prominent than the others. The features common for all eight types of intelligence are: autonomy, changeability and susceptibility to development. (Amstrong, 1994)

Gardner's theory has originated as a reaction to traditionalistic and rigid view on education since, traditionally, teachers are trained and used to teaching all the students in the same way, without minding their mutual differences. One of the most important improvements in education in the last decades has come from extensive research conducted in the field of learning styles. The conclusion was that all students have different profiles of learning. Joy Reid points out some of the dimensions that have been explored in the field of language study and those are: multiple intelligence, perceptive styles of learning, analytical and global learning and reflective and impulsive styles of learning. (Reid, 1998) The paper will explore some of the advantages of raising awareness among students concerning their styles of learning, with a remark that motivation and interest in the process of learning increases students' responsibility for their own process of learning, creating close connection between them in a classroom. Efficient foreign language learning is the biggest challenge for each teacher. The paper will also try to define and explain Gardner's theory on eight types of intelligence and make an overview of its application in the EL classroom. The starting point for this analysis lies in the fact that students learn English in many different ways, which should be considered in the process of lesson planning. In accordance with this, there is a tendency to adjust the education process to each individual and thus make it more interesting, easier and of better quality.

\section{WHAT IS INTELLIGENCE AND HOW IS IT MANIFESTED?}

Gardner's theory of multiple intelligence that appeared in 1983 supported the idea of many different autonomous kinds of intelligence, which resulted in different ways of understanding the human mind. This theory grew apart from the attitude that intelligence should be measured with standard tests. Furthermore, Gardner started following how people around the globe developed the skills they had, which were very important for their lives. As he points out, it is very significant for us to recognize and support all kinds of human intelligence as well as all combinations of two or more types of intelligence. People differ a lot, primarily because they possess different combinations of intelligences. If we realize this, our chances to face numerous problems that happen in the world will increase. (Gardner, 1985)

There is probably no aspect of the modern psychology less understood than intelligence. The notion of intelligence has a powerful effect on a person's social status, educational abilities and a choice of career. Although a lot of attention is dedicated to intelligence, most of us are not able to define it. There is not only one, objective criterion by which intelligence is determined in public or psychology. In most cases, intelligence is accepted and defined as a result on traditional test of intelligence, created by Alfred Binet. Binet's discovery became familiar as an "intelligence test" and had success all over the world. It is true that IQ tests predict results at school with certain accuracy, but when it comes to prediction of professional results and success after the formal education, they are quite unreliable. (Gardner, 1985) Public has generally accepted the theory that intelligence is measured with intelligence tests.

Confusion concerning intelligence also exists in psychology. Part of the confusion concerning psychological definition of intelligence results from the fact that there are several psychological perspectives on intelligence. For example, in modern psychology, the term intelligence can be defined in two ways. The first way is the use of intelligence for practical purposes, such as writing books or designing a new computer. The second way is the use of intelligence in mental processes which would cause intelligent acts. On one hand, there is an assumption that each intelligent act is connected to unique mental process. On the other hand, it seems that each separate mental ability is the foundation of all intelligent achievements. (Kail, 1985) According to one opinion, Mozart was born with the talent for writing music. According to second opinion, Mozart's music is the result of time and place in which he lived and created. In other words, Mozart was at the right place in the right time to develop unique mental processes needed for writing music. This would mean that anyone could have written what he wrote. (Arnold \& 
Fonseca) None of the two opinions is acceptable in practice.

Gardner's theory suggests alternative definition of intelligence which is based on different approaches and points of view on human mind. Gardner primarily suggests pluralistic perspective on mind, recognizing many different aspects of knowledge, considering the fact that people have cognitive power and cognitive styles. (Gardner, 1985) This view on intelligence shows that the final number of mental processes leads to a bunch of intelligent human activities and actions. This kind of intelligence is most noticeable in the process of solving problems. According to Gardner, the problem solving skills permit an individual to take a certain path in order to achieve certain goal. Creation of a final product is crucial to gaining knowledge and its transfer, or expressing certain points of view or feelings. Solving problem situations vary substantially from writing a story to making a pair of shoes. The products also vary from scientific theories, musical compositions to successful political campaigns. (Gardner, 1985)

A question about connection between learning styles and multiple intelligence is very important in education, since even today, many teachers (in this case only English teachers will be referred to) are still unsure about it. They are very often prone to equating multiple intelligence with learning styles. For example, perceptive styles of learning, such as visual and kinesthetic are very often confused with spatial and bodily-kinesthetic intelligence. In order to separate these two concepts, an example about two persons who want to develop their musical intelligence can be used. One of them can go to a store and buy a disk of their favorite music, take it home and listen to it, trying to play what they heard. The second person buys the music, reads and studies it, after which he tries to play the music. Both persons are working on development of their musical intelligence in two different ways. Learning style of the first person is auditory, while the learning style of the second person is visual. (Schumann, 1997) Therefore, learning styles are different approaches or ways of learning. Learning style can vary from task to task.

Multiple intelligence theory was formed in the light of biological origin. Before he came up with the list of eight types of intelligence, Gardner consulted several different sources. He wanted to make a clear distinction between intelligence on one, and talent or skill on the other hand. In his endeavor to do so, he was deliberately provocative in word choice. He identified several basic criteria that each type of intelligence has to meet in order to be designated as intelligence.

The first criterion is a study of brain damage. When people suffer brain damage as a result of the injury, one type of intelligence is often damaged. For example, if a person suffers damage to the left frontal lobe, their linguistic intelligence can be severely damaged. That person may have problems with reading, writing, and speaking, but will still have the ability to do mathematical calculations, to dance and to sing. What Gardner in fact suggests is the existence of eight autonomous brain systems. According to his assumption, if one loses the ability in one area while others are spared, it means that the existence of only one type of intelligence is impossible.

The second criterion are exceptional individuals. We often notice a high level of intelligence that some people posses. Some of these individuals can calculate huge numbers in their heads, or they can play a piece of music after hearing it only once. Scientists are people who demonstrate an incredible ability in one type of intelligence, while they are usually very weak in others.

The history of development is the third criterion. Each intelligence has its own developmental history, its gradual growth during childhood, its peak period in the course of a few years, and finally, the period of gradual decline. Musical intelligence, for example, reaches its peak early and linguistic intelligence can reach that peak very late.

Next criterion is evolutionary history. Each intelligence has its roots in the evolutionary history of man. For example, archaeological testimonies support the existence of early musical instruments. On the other hand, the drawings in the Lascaux caves are good examples of spatial intelligence.

Psychometric findings is the next criterion. Support to the theory of multiple intelligences can be found in many of the standard tests. Weschsler's intelligence scale for children involves sub-tests, which are based on a number of different intelligences.

Psychological tasks is the sixth criterion. We can look into a psychological study and make sure that the separate types of intelligence exist. For example, individuals can improve a specific skill, such as solving arithmetic problems, but they do not need to know how to read. Similarly, individuals may remember words or names very 
well, which does not have to be a case with faces. The tasks seem independent from one another.

The last criterion is a system of symbols. All types of intelligence are subjected to symbolization. There are, for example, different kinds of languages such as spoken and written language, graphical languages, computer languages, ideographic languages. Only those types of intelligence that met most or all of the above mentioned criteria, were labeled as intelligence by Gardner. (Gardner, 1985)

\section{EIGHT TYPES OF INTELLIGENCE}

Having established the main criteria of intelligence, Howard Gardner has identified seven types of intelligence, and since then has added eighth. This list is by no means final. As Gardner points out, the importance is not in the number of intelligence types but in the plurality of intellect. (Gardner, 1985) Each person has a raw biological potential. All people are different when it comes to different profiles of intelligence that they are born with, and the ways in which these profiles develop. Weinreich claims that many people are surprised by certain categories of intelligence that Gardner has chosen, because they never think of them as associated with intelligence. These categories are thought about more like the talents or abilities. (Weinreich, pp. 47-65)

Bodily-kinesthetic intelligence is the ability to use the body for expressing ideas and feelings and solving problems. This includes physical skills such as coordination, flexibility, speed and balance. A teacher of a foreign language can help their students develop their bodilykinesthetic intelligence by providing opportunities for physical challenges during the class.

Intrapersonal intelligence is the ability of a person to understand themselves, their own strengths, weaknesses, moods, desires and intentions. This includes skills such as understanding how the individual is similar to or different from others. At the same time, this kind of intelligence implies a good control of emotions, and the knowledge of what to do and how to act when an individual is angry or sad. A teacher can help students develop their intrapersonal intelligence by allowing them to express their preferences and to find their own learning styles.

Interpersonal intelligence is the ability to understand the feelings, moods, motivations and intentions of others. This includes skills such as pragmatic responses to other people and gathering of people on joint projects. A teacher of English as a foreign language can help students develop this ability through activities which involve them in problem solving situations.

Linguistic intelligence is the art of using words in both written and oral communication. This intelligence includes skills such as memorization of information, persuasion of others to assist in carrying out a task. People with linguistic intelligence are highly skilled speakers, good in debates and discussions, who learn by memorizing words. They are very good at learning foreign languages and the language structure. A teacher can help students develop linguistic intelligence by providing a variety of materials for reading, listening and writing, and creating more opportunities for interaction among students.

Logical-mathematical intelligence involves good skills in handling numbers as well as good logical reasoning. Occupations of engineers, doctors, scientists, mathematicians and economists usually apply to this type of intelligence. A teacher can help students develop logicalmathematical intelligence by bringing instruments for experiments, by letting them play with numbers or use simple machines and computer programs. Students should be encouraged to think about cause-effect relationships.

Musical intelligence is the ability to feel the rhythm, pitch and melody. People with prominent musical intelligence show greater sensitivity to sound, rhythm and music. They have good hearing, they sing well, play instruments and compose. At the same time, they have welldeveloped language skills, and commonly use sounds as the means of memorizing. This type of intelligence applies to occupations of a musician, composer, singer, orator, or writer. A teacher encourages the students by letting them make their own rhymes and music during the class.

Spatial-visual intelligence means a good orientation in space, good observation of lines, shapes and colors. For visually intelligent students in the English language class will be best if a teacher provides materials such as maps, where students have to locate an object that has some connection to the unit. People with advanced visual-spatial intelligence are very good architects.

Naturalistic intelligence refers to nature, connection with it as well as understanding of it. People with strong naturalistic intelligence easily recognize and classify plants, animals and 
minerals. Best occupations for this type of intelligence are biologists, agronomists, farmers and gardeners. Students can develop naturalistic intelligence by focusing their attention on the world outside the classroom.

The theory of multiple intelligences at first was developed as a report on human skills and knowledge that could have been subjected to empirical tests. When Gardner wrote his crucial piece of work Frames of Mind in 1985, he believed that his work will be interesting only to people who were dealing with developmental psychology. However, developmental psychologists were not very interested in Frames of Mind, they ignored it. It is interesting that this work attracted teachers. It seems that the theory of multiple intelligence indicated many educational issues worth considering. In 1994, Thomas Armstrong (Amstrong, 1994) synthesized these ideas about multiple intelligence into four key points that educationists believed the most interesting in this theory:

1. Each person has all eight types of intelligence. For each person eight types of intelligence work together in a unique way. Some people have majority, most or all of the eight types of intelligence very well developed. All of these types of intelligence are very well developed within a small group of people. However, some people have very low level of the eight types of intelligence, while majority of us are in the middle, with few well developed intelligences, and few very bad developed intelligences.

2. Intelligence can be developed. Gardner claims that all human beings have the capacity to develop all eight types of intelligence to a high level, with proper encouragement, instruction and practice.

3. Intelligences work together in complex ways. None of them has an independent existence. Intelligences are always interacting with each other, and they can evolve. For example, to make lunch, one has to read the recipe (which requires linguistic intelligence), then to double or triple the ingredients depending on the number of people who eat (mathematical intelligence), and to prepare a menu which satisfies the guests (interpersonal intelligence).

4. There are many different ways of being intelligent. There is no standard number of features that one needs to possess in order to be considered intelligent. For example, there are people who are not very good at dancing but are very skilled in construction. Both of these activities require possession of bodily-kinesthetic intelligence.

With his theory of multiple intelligence, Howard Gardner has not made a curriculum or a model to be used in schools. Educators and teachers have taken this theory with the agreement to apply it to the curriculum in the USA. (Hoerr, 1997) All that has been stated so far is very helpful for the English language teaching profession, because the theory of multiple intelligence helps in understanding the diversity that is found in students, and finding a way to encourage these differences in a classroom. Language teachers are responsible for creating a curriculum which provides them with a material to point out the differences during the lessons. Much of what we include in the programs of foreign languages is based on tradition. English teachers are expected to know the methods of teaching and testing, theory, grammar, etc. Therefore, many curricula include courses in all these areas. Educational program, on the other hand, is expected to include teachers in the latest and most creative pedagogical courses of foreign languages. When new concepts and ideas are adopted, teachers will have the task of integrating them into existing programs.

\section{APPLICATION OF THE THEORY OF MULTIPLE INTELLIGENCE IN THE CLASSROOM}

The biggest challenge for any foreign language teacher is the use of Gardner's theory during the class. This is never an easy task, mainly because of the often large number of students in a classroom, and their difference in age. A good teacher should constantly be aware of this and adjust their lesson plans to the needs of each individual. However, in practice, as always, it is very easy to state and accept something, but it is much more difficult to implement it. The theory of multiple intelligence offers the teachers of English as a foreign language a way to try and find their techniques of teaching, constantly keeping in mind the differences among people. (Gutloff, 1996) There are lots of ways to follow this theory in order to present the teachers with the ways of applying it in the classroom.

As it was already pointed out, Gardner believes that all people possess many types of intelligence, but differ in their combinations and amounts. The lack of any kind of intelligence can be improved during the training and practice. The theory of multiple intelligence does not dictate the teachers what and how to teach, but it provides a 
good basis for creating a curriculum which would help them to become better at teaching. (Campbell, 1997) Education becomes successful only when the differences between students are understood, analyzed and the materials adjusted to them. Therefore, a successful teacher, the one who actively responds to these differences, will help all students to discover and develop their talents and advantages. By accessing the theory of multiple intelligence, language is not seen as limited to the linguistic perspective, but it encompasses all aspects of communication. (Richards \& Rodgers, 2001) In accordance with this, foreign language teachers should not regard themselves only as language teachers. They should also take the role of a facilitator, observer, creator of curriculum and instruction, researcher, analyst, and conductor. Several criteria for good organization of English lessons will be briefly mentioned here, along with suggestions of activities for each individual intelligence.

Well planned lessons would have to meet some of the criteria such as diversity, flexibility and connectivity. (Richards \& Rodgers, 2001) Since each individual has a unique cognitive profile, there is no single formula for teaching. In fact, there may be as many models of lectures as there are teachers. Language teachers can use Gardner's theory as an introduction to the lesson, or it can be used throughout the class. It can be used every day or occasionally. The courses can be planned either alone or in cooperation with other colleagues. No matter which option you choose, the methods should be adapted to the teaching unit. One of the goals of multiple intelligence pedagogy is that foreign language students become creators of their own experience in learning, in order to be goaloriented and therefore more fulfilled and happier. (Richards \& Rodgers, 2001)

Intelligence is best manifested in the process of solving problems in everyday situations. In the process of language learning, good activities in a class are applicable to the context of real life, because we need to emulate. Therefore, students often gladly take the roles and identify with the situations. Two activities that will be described here can be applied during a foreign language class. One of these activities is related to the group activity based on the eight types of intelligence. The teacher organizes eight "cells," or centers for learning in the classroom, which correspond to the different types of intelligence. Students are divided into eight groups and each group spends certain time on each station. After a while, students swap their groups in a specific order for a limited period of time. In this way, all students face their weaknesses and strengths concerning language learning. They exploit their intelligence in a creative way, because at the same time they observe and work with their peers who have experienced various degrees of intelligence from them. In this way students learn from each other. (Arnold \& Fonseca, p. 24)

Another way to activate and engage students in foreign language learning are projects. Students' projects can be based on a curriculum or a teaching unit, with the aim of promoting independent learning. During the projects, students learn to ask questions relevant to the research, to identify the different sources, to initiate and implement activities. By working on these projects, students engage several types of intelligence. What is probably even more important, by initiating and developing projects of their choice, students acquire great autonomy of learning skills. (Brown, 1994)

One of the tendencies in teaching English as a foreign language is to help students gain knowledge and information. Therefore, selection of appropriate materials and creative use of them should be the main demand of foreign language teachers. Multiple intelligence theory is a challenge for teachers of foreign languages, not just in terms of lesson plans and activities, but also in terms of searching teaching materials. As far as materials and teaching aids are concerned, they can be different, such as books, articles, pictures, DVDs, VCRs or cassettes. Here are some suggestions of the activities for different types of intelligence that could be applied in a foreign language classroom. The proposals were put forward by Jane Arnold and Carmen Fonseca. (Arnold \& Fonseca, p. 25)

Students with logical-mathematical intelligence like problem solving situations, challenges and working on projects. The most suitable questions for this group of students are: "How would you solve this?, What would a scientist say about this problem?" The best activities for students with this kind of intelligence are displaying records, statistical analysis, devising puzzles, comparing and contextualizing material and classifying ideas. (Gardner, 1985) Students will enjoy the scientific work. Famous people with this type of intelligence as Plato, Bill Gates, Michael Pupin.

As far as spatial intelligence is concerned, students should have access to activities that will allow them to take pictures, arrange, build mazes, design, build and draw. The best questions for them are: "How would you present 
it with a chart!" English lesson activities that will stir up the students with strong spatial intelligence are making mind maps, or rearranging things in the room. Famous person with this type of intelligence is Steven Spielberg.

A student with developed musical and rhythmical intelligence is sensitive to sounds and has the ability of responding to them. Memory games, or converting an essays or a film into a musical are the best activities for this type of students. In presentations they use music to highlight the meanings. To develop this type of intelligence the most suitable activities are so-called jazz songs (jazz chants) which use jazz rhythms to illustrate the natural stress and intonation in the English language conversation. They are an innovative and exciting way of developing speaking and listening skills, using everyday language structures. Famous people with this type of intelligence were Mozart and Leonardo Da Vinci.

For students of a prominent bodily-kinesthetic intelligence will be a real pleasure to participate in sports, picnics, or role-playing. Since they Enjoy moving, the use of body is very important for them in the learning process. These students should be allowed to change the seating position, rearrange things in the classroom, simulate, or use pantomime. The question that they should be asked is: "How do you react to that?". Famous people with this type of intelligence are Meryl Streep and Martina Navratilova.

Students with strong linguistic intelligence like to have interesting graphics, posters and slogans, in their surroundings. They are sensitive to language and sarcasm, especially to contempt. They should be allowed to read dialogues, use assertions, teach other students and be involved in a discussion. A good question for them is: "What is your opinion?" They express in the best way through the presentation of their own experiences, group interaction, writing and speech-making, creative writing, and creating crossword puzzles on a particular topic. They like to talk, to argue, tell jokes, reflect, and a teacher is to exploit this fact. Famous people with strong linguistic intelligence are Socrates and Matija Bećkovć.

Since interpersonal intelligence means the capacity of negotiating, making teams, listening to others and influencing on them, students with this kind of intelligence should be given the opportunity to participate in as many classes of group work and cooperative learning. These students do not like to work independently and the best question for them would be: "What have we learned today?"

In contrast to those with strong interpersonal intelligence, students with intrapersonal intelligence are characterized with self-reliance and individual work. Too many questions, activities and forcing to join the group, will create resistance in these students towards the subject. These students are usually very rare in the classroom and they like to enjoy their solitude, according to which they should be allowed to work independently. A teacher could engage these children to explore independently, specifying the topics that are not covered by the lesson. In this case, intrapersonal students would share their findings or results with the rest of the group in some of the next classes. The most appropriate questions to boost their desire to study are: "What would you do if you were the author of today's lesson? How would you feel if ...?" Famous people with strong intrapersonal intelligence who liked to enjoy their solitude and individuality were Ivo Andric and Socrates.

In order to help children develop naturalistic intelligence, English language teachers should take their students to nature where they could collect leaves, rocks, bugs, flowers, etc. These activities are very interesting to both younger and older students. A teacher can ask students to recognize different types of plants in the schoolyard, to learn different names of animals, or collect pictures of animals in order to acquire new vocabulary.

\section{CONCLUSION}

In lessons of English as a foreign language it is possible to motivate students by activating multitude ways of their thinking and using the tasks related to different types of intelligence. Providing a variety of language activities that stimulate different types of intelligence numbered by Gardner, enables the engagement of memory "routs" which are necessary in a long-term learning. A teacher does not have to provide the activities for all types of intelligence in one language lesson, but he should find an approach that will incorporate each of these types of intelligence in the process of his teaching. Students' belief in successful participation in a task can be affected with the way teachers present material to them. The theory of multiple intelligence is a useful tool in planning activities for a foreign language class, challenging for both students and teachers. The moment students become aware of their abilities, their confidence and self-esteem will increase, and lead them to success in a foreign language learning. 
Application of Gardner's theory has been debated in the process of education. An ideal learning should imply the development and growth of an individual in all aspects. For this reason, in today's language learning, it is not enough to insist only on linguistic competence and communication. Gardner explains the social benefits of applying this theory saying that If we can mobilize the full range of human ability, not only will people feel better and more competent, but also more engaged and more able to connect with the rest of the world for the sake of the collective good. (Gardner, 1985) These Gardner's words have deep meaning, because our society requires multilingual citizens who are able to set and achieve goals, who know how to find the information needed for learning outside the classroom, who know how to collaborate, who are generally efficient, and can solve multiple problems in every possible context. The application of multiple intelligence theory in the classroom can help to achieve these goals. As this paper points out, we should realize the importance of different approaches to individuals in foreign languages teaching, in order to achieve high-quality, long-lasting and better foreign language acquisition.

\section{Works Cited}

Amstrong, T. (1994). Multiple Intelligences in the Classroom. Alexandria: VA: ASCD.

Arnold, J., \& Fonseca, C. (n.d.). Multiple Intelligence Theory and Foreign Language Learning: A Brainbased Perspective. International Journal of English Studies. University of Murcia, 123.

Brown, D. H. (1994). Methodology. San Francisco.

Campbell, L. (1997). How Teachers Interprete MI Theory. Educational Leadership.

Gardner, H. (1985). Frames of Mind: The Theory of Multiple Intelligences. New York: Basic Books.

Gutloff, K. (1996). Multiple intelligences. National Education Association of the United States .

Hoerr, T. R. (1997). Frog Ballets and Musical Fractions. ASCD .

Kail, R. (1985). Human Intelligence: Perspectives and Prospectives. New York: W.H. Freeman and Company.

Reid, J. (1998). Understanding Learning Styles in the Second Language Classroom. Upper Saddle River: NJ: Prentice Hall Regents.

Richards, J., \& Rodgers, T. (2001). Approaches and Methods in Language teaching. London: Cambridge University Press.

Weinreich, U. (n.d.). The Varieties of Intelligence: An Interview with Howard Gardner. New Ideas in Psychology .

Received for publication: $\quad 02.05 .2013$

Revision received: $\quad 03.06 .2013$

Accepted for publication: $\quad 29.06 .2013$

\section{How to cite this article?}

Style - APA Sixth Edition:

Čukić, S. (2013, 07 15). Multiple intelligence theory and its application in the foreign language classroom. (Z. Čekerevac, Ed.) MEST Journal, 1(2), 146-154. doi:10.12709/mest.01.01.02.14 
Style - Chicago Fifteenth Edition:

Čukić, Sanja. "Multiple intelligence theory and its application in the foreign language classroom." Edited by Zoran Čekerevac. MEST Journal (MESTE) 1, no. 2 (07 2013): 146-154.

Style - GOST Name Sort:

Čukić Sanja Multiple intelligence theory and its application in the foreign language classroom [Journal] = Multiple intelligence theory in FL classroom // MEST Journal / ed. Čekerevac Zoran. Belgrade : MESTE, 07 15, 2013. - 2 : Vol. 1. - pp. 146-154. - ISSN 2334-7058 (Online); ISSN 23347171.

Style - Harvard Anglia:

Čukić, S., 2013. Multiple intelligence theory and its application in the foreign language classroom. MEST Journal, 15 07, 1(2), pp. 146-154.

Style - ISO 690 Numerical Reference:

Multiple intelligence theory and its application in the foreign language classroom. Čukić, Sanja. [ed.] Zoran Čekerevac. 2, Belgrade : MESTE, 07 15, 2013, MEST Journal, Vol. 1, pp. 146-154. ISSN 23347058 (Online); ISSN 2334-7171. 